\title{
wiiw
}

\section{FEBRUARY 2020}

\section{Working Paper 176}

\section{Does Employment Protection Affect Unemployment?}

\section{A Meta-analysis}

Philipp Heimberger

The Vienna Institute for International Economic Studies Wiener Institut für Internationale Wirtschaftsvergleiche 



\title{
Does Employment Protection Affect Unemployment? A Meta-analysis
}

\author{
PHILIPP HEIMBERGER
}

Philipp Heimberger is Economist at The Vienna Institute for International Economic Studies (wiiw) and Institute for Comprehensive Analysis of the Economy at the Johannes Kepler University, Linz.

Funding from the Austrian Ministry of Social Affairs is gratefully acknowledged.

The author thanks Sebastian Gechert, Robert Stehrer, seminar participants at the IMK Düsseldorf and at the Johannes Kepler University Linz as well as two anonymous referees for providing excellent comments and suggestions on earlier versions of this paper. All remaining errors are mine. 



\section{Abstract}

Despite extensive research efforts, the magnitude of the effect of employment protection legislation $(E P L)$ on unemployment remains unclear. Existing econometric estimates exhibit substantial variation, and it is therefore difficult to draw valid conclusions. This paper applies meta-analysis and metaregression methods to a unique data set consisting of 881 observations on the effect of EPL on unemployment from 75 studies. Once we control for publication selection bias, we cannot reject the hypothesis that the average effect of EPL on unemployment is zero. The meta-regression analysis, which investigates sources of heterogeneity in the reported effect sizes, reveals the following main results. First, the choice of the EPL variable matters: estimates that build on survey-based EPL variables report a significantly stronger unemployment-increasing impact of EPL than estimates developed using EPL indices based on the OECD's methodology, where the latter relies on coding information from legal provisions. Second, we find that employment protection has a small unemployment-increasing effect on female unemployment, compared with a zero impact on total unemployment. Third, using multi-year averages of the underlying data tends to dampen the unemployment effects of EPL. Fourth, product market regulation is found to moderate the effect of EPL on unemployment.

Keywords: Unemployment; labour market institutions; employment protection; meta-analysis

JEL classification: C54; C83; E24 



\section{CONTENTS}

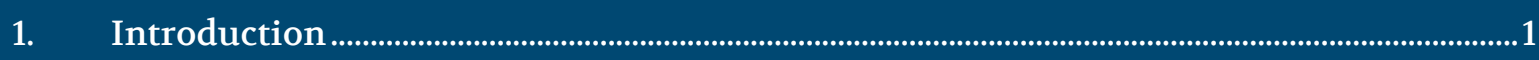

2. Theory and quantification of employment protection ........................................................... 3

2.1. Theoretical views on how employment protection affects unemployment .................................

2.2. Quantification and the quest for understanding employment protection..................................4

2.3. The econometric literature on the EPL-unemployment nexus ............................................5

3. Constructing the meta-study data set on the EPL-unemployment relationship .............7

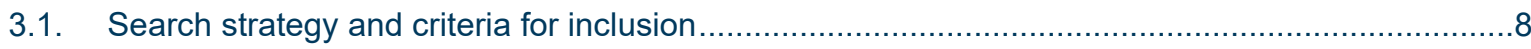

3.2. The EPL-unemployment nexus: comparable effect sizes and corresponding standard errors........9

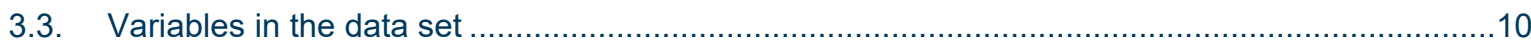

4. Estimating average EPL-unemployment effects while considering potential publication selectivity ................................................................................................................................14

5. What factors explain the heterogeneity in reported EPL-unemployment estimates?..

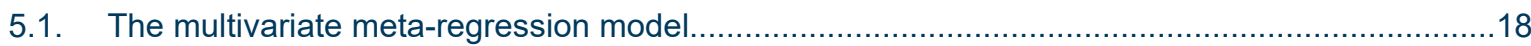

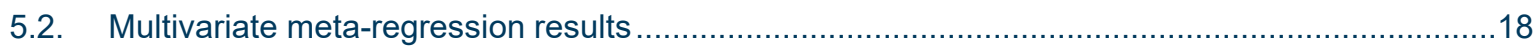

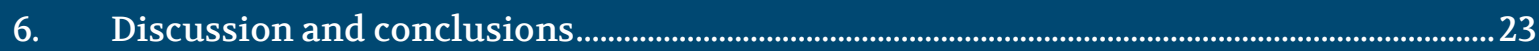

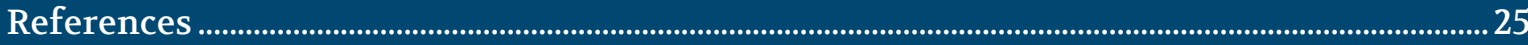




\section{TABLES AND FIGURES}

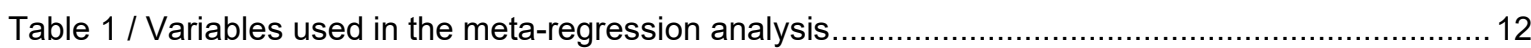

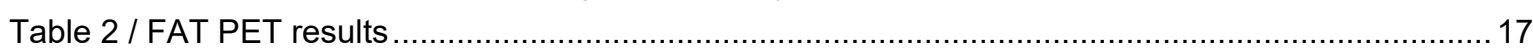

Table 3 / Multivariate regression results (starting from general-to-specific modelling) .......................21

Figure 1 / Employment protection legislation and unemployment rates in 28 OECD countries.............. 8

Figure 2 / Precision and effect size of EPL-unemployment estimates ......................................... 14 


\section{Introduction}

One of the most fundamental questions in economics is about the determinants of unemployment, and high rates of unemployment remain a key policy concern. Several explanations have been put forward to explain the evolution of unemployment rates. One prominent explanation suggests that employment protection legislation (EPL) is a major factor. In this context, the increase in unemployment in most OECD countries in the aftermath of the financial crisis of 2007/08 has trigged a new wave of interest in the relationship between EPL and unemployment (e.g. Amable and Mayhew 2011; OECD 2016; Cahuc et al. 2019). The view that 'structural' reforms geared towards reducing employment protection can help to lower unemployment has greatly influenced policy debates during the post-crisis era. In Europe, several governments have introduced measures to increase the flexibility of existing labour regulations to make it easier for firms to hire and fire workers, leading to intense debates about the actual impact of such deregulation measures (e.g. Eggertsson et al. 2014; Campos et al. 2018; Duval and Furceri 2018). However, a focus on tackling unemployment by calling for labour market deregulation has strongly shaped policy-making since at least the 1990s (e.g. OECD 1994; IMF 2003).

Is the focus on employment protection supported by robust evidence concerning the direction and magnitude of the effect of EPL on unemployment? In theory, this effect is ambiguous. On one hand, the standard competitive model predicts that employment protection will increase unemployment, as employers are reluctant to hire workers because they fear that these workers cannot be laid off easily (e.g. Addison and Teixeira 2003). On the other hand, more rigid EPL may increase job retention, because companies lay off fewer employees in the face of high severance pay and procedural costs of dismissal, especially during economic downswings. In essence, the theoretical expectations about the direction and magnitude of the effect of EPL on unemployment are not clear-cut (e.g. Bertola 1990). Understanding the relationship between EPL and unemployment is therefore also an important question for empirical research. However, existing studies report mixed results concerning the impact of EPL on unemployment. Whereas some papers indeed provide evidence for the view that more rigid hiring and firing regulations push up unemployment (e.g. Elmeskov et al. 1998; Di Tella and MacCulloch 2005; Feldmann 2009; Holt and Hendrickson 2017), other studies contradict these findings by reporting negative or zero effects (e.g. Baccaro and Rei 2007; Dutt et al. 2009; Stockhammer and Klär 2011; Avdagic 2015). In sum, the extant literature has not been able to present convincing econometric evidence to resolve conflicting theoretical arguments. Relevant studies often differ markedly based on the structure of the data and the details of the econometric specification. Considering the wide range of estimates reported in the literature, it is therefore quite challenging to undertake generalisations based on traditional literature reviews.

This article contributes to the literature by presenting the first quantitative literature review of the effect of employment protection on unemployment based on meta-analysis and meta-regression techniques (e.g. Stanley and Doucouliagos 2012) that allow us to conduct formal hypothesis tests and draw valid statistical inferences. As it is well known that differences in econometric specification and in the data used can have a sizeable impact on empirical estimates, this paper sets out to make sense of the substantial variation of estimates concerning the relationship between EPL and unemployment. 
Wiiw Working Paper 176

We tackle two main questions. First, what does the existing evidence tell us about the effect of EPL on unemployment? The meta-analysis, in combination with formal tests on publication selection bias, will provide answers to this question as we conduct a comprehensive survey and quantitative analysis of the relevant econometric estimates on the relationship between EPL and unemployment (see sections 3 and 4). Second, what factors explain the heterogeneity in the reported results on the EPL-unemployment nexus? We use meta-regression analysis to address this question by exploring the impact of the data structure, econometric specification details and publication characteristics on the reported EPL-unemployment estimates (see section 5). 


\section{Theory and quantification of employment protection}

This section focuses on three main issues that are of central importance for conducting the quantitative literature review on how employment protection affects unemployment. First, we present an outline of important theoretical arguments on how employment protection may have an effect on unemployment. Second, we provide a discussion on prominent approaches to measuring employment protection. Third, we give a short (qualitative) overview of the econometric literature on the EPL-unemployment nexus.

\subsection{THEORETICAL VIEWS ON HOW EMPLOYMENT PROTECTION AFFECTS UNEMPLOYMENT}

The theoretical effects of employment protection, understood as the set of restrictions on the ability of the employer to utilise labour, are not clear-cut. The standard competitive model predicts that strict employment protection pushes unemployment upwards: restrictions on the freedom of contract are assumed to increase resource costs; insiders have an incentive to demand higher wages, which reduces the ability and speed of the economy to adjust to exogenous shocks and inhibits the reallocation of labour between sectors, eventually causing dampened job creation and higher unemployment. However, while the standard competitive model predicts that employment protection increases unemployment, one can overturn those results by introducing market imperfections (e.g. Addison and Teixeira 2003). Theory is clear that strict EPL reduces labour fluctuations over the business cycle, but the overall effect on unemployment is not straightforward, as it may depend on the form of the labour demand function, the degree of wage flexibility, labour turnover, the discount rate, and enforcement (e.g. Bertola 1990; Boeri 1999; Boeri and Jimeno 2005).

Importantly, it must be noted that very different labour markets can hide behind the same average unemployment rate. By comparing Portuguese and US labour markets, Blanchard and Portugal (2001) have prominently shown that high employment protection can be a plausible explanation for lower flows both of job creation and job destruction. However, they also argue that the effect of EPL on unemployment remains ambiguous, as EPL affects unemployment duration and worker flows in opposite directions. The focus of this meta-analysis is on the econometric literature concerning the EPLunemployment nexus. We do not meta-analyse the effect of EPL on flows of workers into unemployment and unemployment duration, which is a limitation that could be tackled by future research.

What does macroeconomics have to say about the effect of employment protection on unemployment? On a theoretical level, the crucial question posed by macroeconomists is how the 'non-accelerating inflation rate of unemployment' (NAIRU) is developing. The NAIRU is at the core of modern macroeconomics, building on the proposition that there exists some (unobserved) rate of unemployment at which inflation does not accelerate. The NAIRU has been identified with the idea of a 'natural rate of unemployment' (Ball and Mankiw 2002), which would prevail if all cyclical fluctuations were cancelled out, so that natural unemployment represents structural unemployment that exists independently of all 
temporary and seasonal fluctuations. Friedman famously argued that the level of the natural rate of unemployment 'would be ground out by the Walrasian system of general equilibrium equations, provided that there is embedded in them the actual structural characteristics of the labour and commodity markets' (Friedman 1968, p. 8). As employment protection is certainly an important aspect of the characteristics of modern labour markets, it is not surprising that the follow-up literature on Friedman's seminal contribution has referred to EPL as a potentially important factor. The New-Keynesian literature, which maintains the perfectly competitive model of the labour market as the reference system, but situates its analysis in a framework of market imperfections, has been quite influential when it comes to understanding the evolution of unemployment (e.g. Layard et al. 1991; Nickell 1998). However, while New-Keynesian NAIRU theory provides a systematic approach for thinking about the role of protective labour market institutions in more general terms, it does not offer any straightforward theoretical guidance about the direction and magnitude of the effect of employment protection legislation on unemployment. This leaves us stuck with the previous conclusion that the theoretical effect of employment protection on unemployment is ex-ante ambiguous.

\subsection{QUANTIFICATION AND THE QUEST FOR UNDERSTANDING EMPLOYMENT PROTECTION}

Against the background of the theoretical literature discussed in the last section, several empirical approaches have been developed to quantify the strictness of EPL. Lazear (1990) compares the statutory entitlement of severance payments as well as legally binding notice periods across countries. He does not yet use an elaborated summary index, but instead relies on data such as the number of months of salary given to workers upon dismissal and the number of months' notice required before contract termination. Building on seminal data collection efforts from the early 1990s, Grubb and Wells (1993) use information compiled from legal provisions to construct some of the first summary indicators on employment protection. Eventually, the OECD developed this approach into the most prominent quantitative summary index on EPL, which summarises a selection of legal provisions on employment protection. First published in the OECD's Employment Outlook of 1999 (OECD 1999), the index measures the strictness of EPL using discrete indicators ranging from 0 to 6 , where higher index values point to more rigid employment protection. The OECD completed two major updates of the EPL index, in 2008 and 2013, which allowed for including additional information on legal provisions such as clauses from collective agreements and temporary agency work (OECD 2013). The OECD's overall EPL summary indicator comprises 21 items. ${ }^{1}$ Index computation is based on standardised questionnaires, which have to be filled in by the respective OECD member states and the OECD's secretariat. The information used for index computation is mainly compiled from national labour laws, but some additional sources (such as collective bargaining agreements) are also utilised. The relevant regulations cover aspects such as procedural inconveniences, notice and severance pay, difficulty of dismissal, costs of collective dismissals, fixed-term contracts, and temporary work agencies. These regulations are given numerical scores that represent the strictness of employment protection. They are assigned to one of the 21 items in the overall EPL summary index, and the individual index components are then weighted (see OECD 2013 for details). ${ }^{2}$

These items can be grouped in three sub-indicators: EPL of regular contracts; EPL concerning additional regulations on collective dismissals; and EPL capturing temporary employment.

2 Obviously, any attempt to quantify legal provisions comes with problematic methodological choices. Against the background of the high importance of the OECD's EPL index for policy assessments in respective member states, the construction of the EPL index has been subject to a significant amount of criticism (e.g. Myant and Brandhuber 2017). 
Data collection efforts on employment protection legislation in non-OECD countries, such as in Aleksynska and Schindler (2011) and Avdagic (2015), have also relied on the OECD's methodology. Indeed, as we will see in the upcoming meta-analysis, a large majority of the econometric estimates on the EPL-unemployment relationship have used some version of an EPL index constructed based on the OECD's methodology, including some of the most influential studies (e.g. Scarpetta 1996; Blanchard and Wolfers 2000; Nickell et al. 2005). Nevertheless, there is also a selection of alternative indices that quantify the strictness of employment protection. A thorough treatment of all these measures would be beyond the scope of this paper, but we will mention those alternative EPL variables that have been used in empirical applications relevant to the meta-analysis presented in subsequent sections.

First, there are two alternative indices that rely respectively on the coding of labour laws and additional primary sources to quantify the evolution of EPL (Botero et al. 2004; Deakin et al. 2007). These indices have occasionally been used in subsequent empirical work on the relationship between EPL and unemployment (Dutt et al. 2009; Deakin et al. 2014). Second, the Economic Freedom of the World Index (EFWI) contains sub-indicators on the strictness of hiring and firing regulations that have also been utilised in some of the relevant empirical applications (Bernal-Verdugo et al. 2012; Bernal-Verdugo et al. 2013; Feldmann 2009). The EFWI includes data based on surveys and expert panels, in addition to information compiled from legal provisions. Both the survey data and the data on legal provisions are obtained from external sources (Gwartney et al. 2018), so the EFWI cannot be considered a primarysource index, which stands it in contrast to the indices discussed so far. Third, several econometric papers on the EPL-unemployment relationship have made use of survey-based measures of the strictness of employment regulations, i.e. they do not collect any information from legal provisions but instead construct indices that are exclusively based on surveys of managers and experts that were asked about their assessment regarding the strictness of hiring and firing regulations (e.g. Di Tella and MacCulloch 2005; Feldmann 2013). In subsequent sections, we will be able to provide an answer to the question of whether the use of different EPL variables - the OECD methodology, other primary source indices constructed based on legal provisions, the EFWI index and survey-based measures, respectively - has a significant impact on the reported estimates concerning the relationship between EPL and unemployment.

\subsection{THE ECONOMETRIC LITERATURE ON THE EPL-UNEMPLOYMENT NEXUS}

From the late 1970s to the 1990s, many OECD countries experienced a marked increase in unemployment rates, and the economic literature has extensively studied the explanatory factors for rising unemployment during that period; Bean (1994) and Blanchard (2006) provide prominent qualitative reviews. A substantial strand of this literature has emphasised that labour market rigidities caused by protective labour market institutions are to be considered a major factor behind increasing unemployment rates within OECD countries (OECD 1994; Scarpetta 1996; Siebert 1997; Elmeskov et al. 1998; Blanchard and Wolfers 2000; International Monetary Fund 2003; Nickell et al. 2005). A careful look at many of these papers, however, suggests that the evidence for a positive impact of employment protection on unemployment is modest at best. Nevertheless, the view that strict employment protection is a concern when it comes to unemployment developments has gained traction in policy-making, leading to calls for 'structural' labour market reforms, including requests for reductions in employment protection by 'a wide range of analysts and international organisations - including the European Commission, the Organisation for Economic Cooperation and Development (OECD), and the 
wiiw Working Paper 176

International Monetary Fund (IMF), which have argued that the causes of high unemployment can be found in labour market institutions." (International Monetary Fund 2003, p. 129) Parts of the more recent econometric literature, however, point out that relevant empirical correlations between labour market institutions (in particular, employment protection) and unemployment reported in the literature may not be robust when viewed in the context of different data sets, estimation strategies, country groups and time periods (Baker et al. 2005; Howell et al. 2007; Heckman 2007; Baccaro and Rei 2007; Stockhammer and Klär 2011; Vergeer and Kleinknecht 2012).

After the financial and economic crisis of 2007/08 hit, unemployment rates in most OECD countries increased markedly, especially in Europe (e.g. OECD 2013). Although unemployment rates have eventually fallen after a severe crisis-related surge (to varying degrees and at different speeds across countries), unemployment in several OECD countries remains above pre-crisis levels. These developments have led to renewed interest in the question of how employment protection affects unemployment, but results in the post-crisis literature remain mixed (e.g. Bernal-Verdugo et al. 2012; Avdagic 2015; Heimberger et al. 2017). Based on a qualitative review of the literature, Bean (1994) concluded: "The empirical literature on the causes of high European unemployment is vast, with different authors employing a bewildering variety of econometric specifications and often coming to different conclusions. At times these differences are more apparent than real, reflecting different conditioning assumptions, but at other times they are more substantive" (Bean 1994, p. 576). A lot of additional research has been conducted since Bean's assessment was published in 1994. The literature is now certainly even more voluminous, and the variety of different specifications and conclusions continues to bewilder the interested reader. So far, however, the issue of the significance of different choices regarding data and estimation strategy has not been addressed systematically within a meta-analytical framework, and this paper contributes to closing this gap. In what follows, we will provide the first quantitative summary of the relevant econometric literature on the relationship between EPL and unemployment (see sections 3 and 4), and the use of meta-regression will allow us to explain parts of the wide variation in the reported results (see section 5). 


\section{Constructing the meta-study data set on the EPL-unemployment relationship}

Based on the widely used EPL index provided by the OECD (on the construction of this index, see OECD 2013), Panel A of Figure 1 shows for a sample of OECD countries that, on average, there is a slightly falling trend in employment protection over the period 1985-2013. Panel B of Figure 1 plots the average relationship between the EPL index and unemployment rates for this group of OECD countries. According to this plot, there is substantial variation in the levels of employment protection and unemployment across OECD countries. However, according to this bivariate plot, there is also not much of a systematic relationship between employment protection and unemployment; the EPL index only explains about $1.6 \%$ of the variation in unemployment. However, if one were to conduct a detailed analysis on how EPL affects unemployment, the picture may change, and several aspects need to be considered that might have an impact on the final results: the choice of the EPL measure (the OECD's preferred index as in Figure 1 or other measures?), the type of unemployment (total unemployment or sub-components such as youth, long-term or female unemployment?), the time dimension of the data (what time period?), the composition of the country group (are non-OECD countries included?), the structure of the data (cross-sectional or panel data?), the estimator (OLS with fixed effects or other estimators?) etc. These factors will be accounted for in the meta-regression analysis.

In the next step, we identify the relevant econometric literature on the EPL-unemployment relationship and calculate comparable effect sizes from the reported information. Section 3.1 discusses our data set in the context of the literature search and data collection process. Section 3.2 sheds light on how we obtained comparable estimates of effect sizes and their standard errors. Section 3.3 presents the variables included in the analysis. 
wiiw Working Paper 176

Figure 1 / Employment protection legislation and unemployment rates in 28 OECD countries

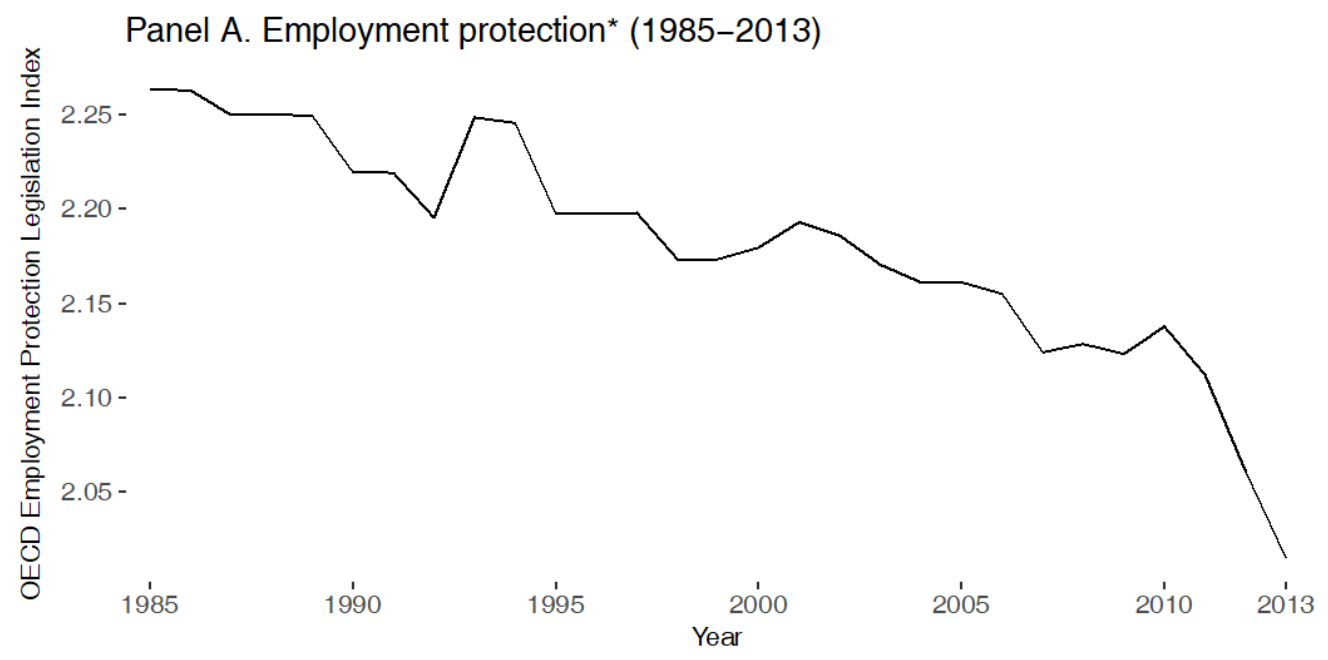

Panel B. EPL and unemployment

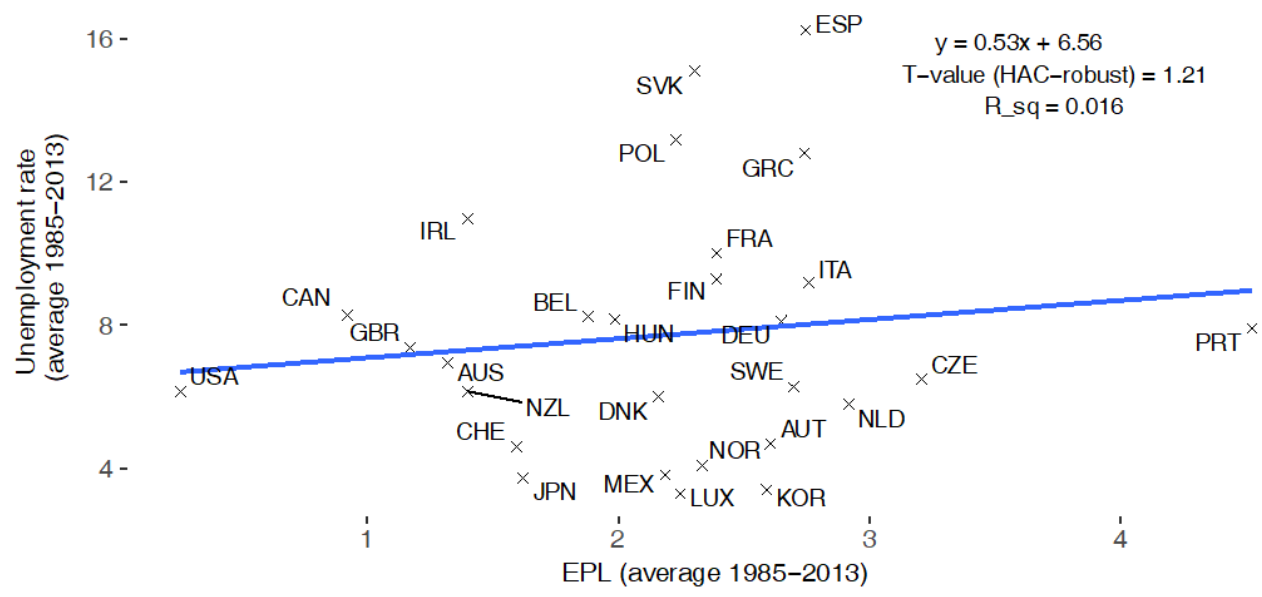

Notes: *Strictness of employment protection, individual and collective dismissals for regular contracts (source: OECD data base). Unemployment represents harmonised unemployment rates as provided by the OECD. See OECD (2013) for details on the methodology used to construct this EPL summary indicator. The EPL data in Panel A depict an unweighted average of the 28 OECD countries that were also included in panel B. Notably, there are missing observations for some countries, so that the average covers the whole time period $1985-2013$ for many countries, but a shorter period for those countries with missing observations.

\subsection{SEARCH STRATEGY AND CRITERIA FOR INCLUSION}

The systematic search and review of the literature for this paper began by tracking down all peerreviewed academic papers on the relationship between employment protection and unemployment. To construct our meta-study sample, we proceeded as follows. To search for papers, we first used (i) Google Scholar and (ii) the EconLit database. We used the following keywords in the search process: "employment protection + unemployment"; "job regulations + unemployment"; and "flexibility + unemployment". Furthermore, we followed up on references cited in empirical studies and reviews of this literature by screening the reference lists. The criteria for inclusion in the meta-study sample are as follows: 
a) Unemployment as the dependent variable and employment protection as explanatory variable: As a condition for being included in our data set, papers use a measure of unemployment as the dependent variable and at least one measure of employment protection as an explanatory variable. To be included, studies had to report results from some variant of the following generic econometric model (note that we ignore subscripts for the purpose of simplification):

$$
U N E M=\alpha+\beta_{1} E P L+\beta_{x} Z_{x}+\varepsilon
$$

where the dependent variable UNEM is a measure of unemployment (e.g. the total unemployment rate, or the youth unemployment rate), EPL is a measure of employment protection, $Z$ is a vector of other explanatory variables, and $\varepsilon$ is the error term. For example, papers that use a measure of employment rates (instead of unemployment rates) as the dependent variable had to be excluded, as did papers using overall indices of labour market regulation (instead of a focus on employment protection).

b) Reported econometric estimates: Only those empirical studies that presented regression results were considered. This restriction excluded numerous papers that present theoretical analysis, descriptive statistics or qualitative reviews without including econometric evidence.

c) Published in peer-reviewed journals: We only included estimates that were published in peer-reviewed journals (in English) prior to November 2019. We excluded other works on the EPL-unemployment nexus (e.g. working papers, book chapters etc.). Peer-reviewed journal publications can be considered to have passed a certain 'quality' check by referees. By following this restriction, we avoid comparisons of estimates that may have a very different level of 'quality'. Furthermore, it is challenging to track down all potentially relevant book chapters and other non-peer-reviewed documents that touch upon the relationship between EPL and unemployment. Therefore, the restriction on peer-reviewed journal papers contributed to ensuring that the coding process remained transparent and manageable.

d) Offered relevant statistics: In order to be included, a paper had to meet certain reporting standards. The requirement was that the paper must have offered statistics (e.g. correlation coefficients and standard errors or t-statistics) from which standardised measures of the impact of employment protection on unemployment could be computed (see section 3.2).

Seventy-five papers were compatible with these criteria. We included all estimates from these papers that met the criteria of inclusion explained above, yielding a total of 881 estimates for the meta-study data set. Table A1 in the supplementary appendix lists the 75 studies that were included. The estimates that were compiled from these papers constitute our total population concerning the EPL-unemployment relationship.

\subsection{THE EPL-UNEMPLOYMENT NEXUS: COMPARABLE EFFECT SIZES AND CORRESPONDING STANDARD ERRORS}

The estimates reported in the literature use different effect sizes, which are not directly comparable. To illustrate the magnitude of the effect of employment protection on unemployment, we need to make all estimates comparable. The partial correlation is used as the preferred standardised effect. In the context of this paper, partial correlations measure the impact of EPL on unemployment while holding other 
factors constant, and they can be directly calculated from the reported regression output. The two big advantages of the partial correlation coefficient are that it can be meaningfully compared across papers (because it is a unitless measure bounded between -1 and 1 ), and it can be calculated for a much larger set of estimates than other effect-size measures. Formally, the partial correlation coefficient is given by:

$r=\frac{t}{\sqrt{t^{2}+d f}}$

where $t$ is the t-statistic of the relevant regression coefficient and df denotes the degrees of freedom of this t-statistic (Stanley and Doucouliagos 2012, p. 25). The standard error of the partial correlation coefficient (ser) is given by: ser $=\sqrt{\frac{1-r^{2}}{d f}}$, where $\mathrm{r}$ is the partial correlation coefficient and df denotes the degrees of freedom.

\subsection{VARIABLES IN THE DATA SET}

In what follows, we introduce the data we obtained from the 75 studies that fit our inclusion criteria. Due to space constraints, this section will only report some important descriptive statistics. However, Table A2 in the supplementary appendix reports additional details on the underlying data set along several characteristics for the 75 studies that were included.

Measures of the dependent variable (unemployment): Recall that the dependent variable in the metaanalysis is a measure of unemployment (see equation 1). We account for differences in the dependent variable by distinguishing estimates that use the total unemployment rate (i.e. the percentage of the total working-age population that is unemployed), the youth unemployment rate, the long-term unemployment rate, the female unemployment rate and other (unspecified) types of unemployment, respectively. Table 1 includes the mean and standard deviation for all of these different unemployment variables. The mean of all these dummy variables can be interpreted in percentage terms, which provides important descriptive information: more than two-thirds of all estimates use the total unemployment rate; youth unemployment, long-term unemployment and female unemployment account for $14.1 \%, 7.8 \%$ and $2.7 \%$, respectively.

Measures of employment protection: Different indicators have been used to quantify EPL. Most prominent are summary indicators based on the OECD's methodology. We code three dummy variables for alternative EPL variables: other primary-source EPL indices based on legal provisions; the Economic Freedom of the World Index (EFWI) on hiring and firing regulations; and purely survey-based measures of employment protection. Details on and references to those different EPL measures can be found in section 2.2.

The interpretation of the estimates obtained from using different EPL measures may differ. For example, when a study uses a summary index where higher values indicate stricter employment protection, a positive coefficient of the EPL variable indicates an unemployment-increasing association. However, when the estimate is based on an index where higher values indicate more flexibility of hiring and firing regulations, the interpretation of a positive coefficient estimate would be the other way around. We deal with this potential confusion in the interpretation of estimates by transforming the partial correlations and their corresponding t-statistics of those variables that are constructed so that higher EPL values indicate less strict employment protection. We do so by multiplying them with (-1). This transformation makes the 
direction of all estimates comparable (no matter which EPL measure they use) and allows for the general interpretation that a positive partial correlation coefficient indicates an unemployment-increasing effect of EPL.

Data characteristics: We also explore the type of data used. Hence, we consider whether a study used cross-sectional data instead of panel data, which is the case for only $4 \%$ of the estimates. Additionally, we include a dummy variable capturing the use of post-crisis data (i.e. the inclusion of data points from the year 2009 onwards). And we code whether the respective estimates are based on annual data or multi-year averages (YearAverage). The economic rationale for using (mostly five-year) averages of the data is to take into account that labour market institutions only change slowly. Averaging intends to dampen possible effects of the business cycle and allow for more reliable 'long-run' causal interpretations (e.g. Baccaro and Rei 2007; Stockhammer and Klär 2011).

Country composition: If the level of development played a role, the EPL-unemployment relationship would be influenced by the underlying country sample (e.g. Addison and Teixeira 2003). We thus control for whether an estimate uses OECD countries, non-OECD countries or a mix of OECD and non-OECD countries. It should be noted, however, that the large majority of estimates (78.3\%) are based on OECD country samples.

Econometric details: We account for differences in the estimators used by coding a variable for Generalised Methods of Moments (GMM), Ordinary Least Squares (OLS), Random Effects and Feasible Generalised Least Squares (FGLS), Two-stage Least Squares approaches (IV), and other estimators (OtherEstimator), respectively.

We also consider whether estimates control for unobserved country heterogeneity (CountryFixedEffects). Furthermore, we check whether the regression model included an interaction term of EPL with some other variable, as several studies emphasise the importance of interaction terms (e.g. Blanchard and Wolfers 2000; Bassanini and Duval 2006). And we consider whether the EPL variable was included with a lag. Several studies explain that they use EPL lags to lessen concerns about simultaneity bias $^{3}$ and to allow for slow adjustment of unemployment to increasing EPL (e.g. Checchi and Garcia-Penalosa 2008; Feldmann 2009; Holt and Hendrickson 2017).

Publication characteristics: We account for various dimensions of the publication process: differences between labour journals and other types of journals; whether a study's primary focus is the EPLunemployment relationship, as opposed to including EPL merely as a control variable; and whether the author(s) of a study have received comments or feedback from other authors publishing in the literature on the EPL-unemployment relationship. ${ }^{4}$

3 Simultaneity concerns refer to potential difficulties with causal interpretation when EPL and unemployment are determined simultaneously: unemployment and employment protection may be endogenous, caused by partly unobserved processes driving EPL and unemployment.

4 The information on the variables 'Primary' and 'CrossAuthor' can be collected based on the footnotes and acknowledgments in the relevant studies. 
wiiw Working Paper 176

Table 1 / Variables used in the meta-regression analysis

\begin{tabular}{|c|c|c|c|}
\hline \multirow[b]{2}{*}{ Variable name } & \multirow[b]{2}{*}{ Variable description } & \multicolumn{2}{|c|}{$(N=881)$} \\
\hline & & Mean & S.D. \\
\hline Partial correlation & $\begin{array}{l}\text { Partial correlation of the impact of employment protection on } \\
\text { unemployment }\end{array}$ & 0.033 & 0.154 \\
\hline \multicolumn{4}{|l|}{ Unemployment measures } \\
\hline TotalUnemployment (used as the base) & $\mathrm{BD}=1$ : Total unemployment rate used as dependent variable & 0.671 & 0.470 \\
\hline FemaleUnemployment & $\mathrm{BD}=1:$ Female unemployment rate used as dependent variable & 0.027 & 0.163 \\
\hline OtherDependentVar & $\begin{array}{l}\mathrm{BD}=1 \text { : Unemployment rate other than total, youth, long-term or female } \\
\text { unemployment used as dependent variable }\end{array}$ & 0.083 & 0.276 \\
\hline \multicolumn{4}{|l|}{ Employment protection measures } \\
\hline EFWIndex & $\begin{array}{l}\mathrm{BD}=1 \text { : Economic Freedom of the World index on hiring and firing } \\
\text { regulations used as regressor }\end{array}$ & 0.028 & 0.166 \\
\hline SurveyBased & $\mathrm{BD}=1$ : Survey-based index on employment protection used as regressor & 0.093 & 0.291 \\
\hline \multicolumn{4}{|l|}{ Data characteristics } \\
\hline CrossSection & $\mathrm{BD}=1$ : Cross sectional data used & 0.040 & 0.195 \\
\hline PostCrisisData & $\mathrm{BD}=1$ : Sample includes data from year 2009 onwards & 0.247 & 0.432 \\
\hline YearAverage & $\mathrm{BD}=1$ : Variables expressed as multi-year averages & 0.170 & 0.376 \\
\hline InteractedEPL & $\begin{array}{l}\mathrm{BD}=1 \text { : Interaction of employment protection variable with some other } \\
\text { variable included }\end{array}$ & 0.110 & 0.313 \\
\hline LaggedEPL & $\mathrm{BD}=1$ : EPL variable is included with a lag & 0.297 & 0.457 \\
\hline GMM (used as the base) & $\mathrm{BD}=1: \mathrm{GMM}$ estimator used & 0.030 & 0.169 \\
\hline OLS & $\mathrm{BD}=1:$ OLS estimator used & 0.585 & 0.493 \\
\hline FGLS & $\mathrm{BD}=1$ : FGLS estimator used & 0.220 & 0.415 \\
\hline IV & $\begin{array}{l}\mathrm{BD}=1 \text { : Instrumental variable and Two-Stage-Least-Squares approach } \\
\text { used }\end{array}$ & 0.085 & 0.279 \\
\hline OtherEstimator & $\mathrm{BD}=1$ : Estimator other than GMM, OLS, FGLS or IV used & 0.081 & 0.272 \\
\hline \multicolumn{4}{|l|}{ Publication characteristics } \\
\hline StandardError & Standard error of the partial correlation coefficient & 0.087 & 0.047 \\
\hline LabourJournal & $\mathrm{BD}=1$ : Study published in a journal focusing on labour economics & 0.098 & 0.297 \\
\hline Primary & $\mathrm{BD}=1$ : Link EPL-unemployment is the primary issue of interest & 0.285 & 0.452 \\
\hline CrossAuthor & $\begin{array}{l}\mathrm{BD}=1 \text { : Author declares receiving feedback from other authors who have } \\
\text { published in this literature }\end{array}$ & 0.257 & 0.437 \\
\hline Prior & $\mathrm{BD}=1$ : Author has published previously in this area & 0.415 & 0.493 \\
\hline \multicolumn{4}{|c|}{ Macroeconomic and institutional control variables } \\
\hline UnemploymentBenefits & $\mathrm{BD}=1$ : Unemployment benefit replacement rate included as control & 0.680 & 0.467 \\
\hline TaxWedge & $\mathrm{BD}=1$ : Labour tax wedge included as control & 0.513 & 0.500 \\
\hline
\end{tabular}

Notes: BD means binary dummy, which takes the value of 1 if the condition is fulfilled and zero otherwise. 
Macroeconomic and institutional control variables: Finally, we consider the inclusion of potentially relevant control variables in primary studies. Several studies suggest that the effect of employment protection might be moderated by the impact of other labour market institutions (e.g. Blanchard and Wolfers 2000; Belot and van Ours 2004; Bassanini and Duval 2006). Therefore, we consider whether the unemployment benefit replacement rate and/or the labour tax wedge are controlled for. Several studies account for macroeconomic factors, such as the growth rate of GDP, the real long-term interest rate and capital accumulation (e.g. Avdagic and Salardi 2013; Stockhammer and Klär 2011; Heimberger et al. 2017). We code dummy variables for these macroeconomic controls. Finally, product market regulation is a potentially relevant moderator variable, as the response of employers to an increase in employment protection may depend on whether product markets are regulated heavily (e.g. Griffith 2007). We therefore consider whether a variable controlling for product market regulation was included in the underlying regression. Additional information concerning the composition of the data in the 75 included studies is available in Table A2 of the supplementary appendix. 


\section{Estimating average EPL-unemployment effects while considering potential publication selectivity}

Information concerning the distribution of the estimates obtained from the literature is available from Figure 2. ${ }^{5}$ This is a funnel plot (e.g. Sutton et al. 2000) consisting of all 881 econometric estimates of the EPL-unemployment relationship that we included in the data set (on the horizontal axis) and the precision of these estimates, where precision is calculated as the inverse of the standard errors of the partial correlation coefficients (on the vertical axis). ${ }^{6}$ Although the unweighted mean (0.03) and median (0.02) are positive but very small in terms of magnitude, ${ }^{7}$ Figure 2 reveals that there is clearly considerable dispersion in the results: the minimum partial correlation coefficient is -0.52 and the maximum is 0.54 ; the standard deviation is 0.16 . The most precise estimates, which can be seen at the top of the figure, are close to the vertical zero effect line.

Figure 2 / Precision and effect size of EPL-unemployment estimates

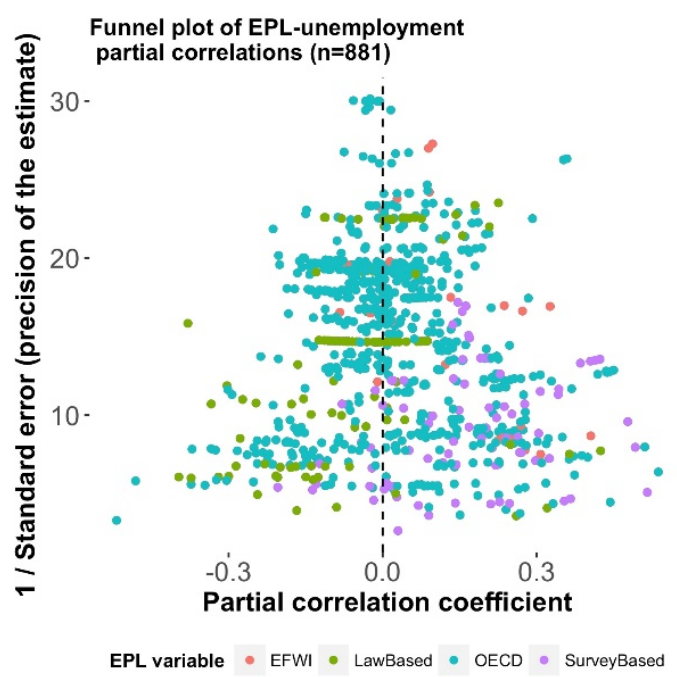

Notes: The figure plots estimates of the partial correlations against the inverse of the corresponding standard error.

For illustration purposes, Figure 2 uses different colours depending on the underlying EPL variable. The large majority of the estimates $(75.7 \%)$ use an EPL variable based on the OECD's methodology, and these estimates are distributed quite symmetrically. However, the contrary is true for the estimates based on purely survey-based measures of employment protection: Figure 2 reveals that although fewer

5 Figure A1 in the supplementary appendix shows a kernel density plot representing the distribution of partial correlations.

$6 \quad$ Figure A2 in the supplementary appendix shows additional funnel plots for subsets of our data set by restricting the number of estimates based on data choices and specification details.

7 According to the interpretation guidelines in Doucouliagos (2011), a partial correlation below 0.07 can be considered to be small. 
estimates use survey-based EPL variables (9.3\% of all observations), they are located mostly to the right of the vertical zero effect line, indicating unemployment-increasing effects of EPL. Two further subsamples represent primary-source EPL indices (other than those based on the OECD methodology), which account for $12.1 \%$ of all estimates, and the Economic Freedom of the World Index on hiring and firing regulations $(2.8 \%)$. At a later point (see section 5 ), we will use meta-regression analysis to test formally whether the choice of the EPL variables has an impact on the reported results when we also control for other confounding factors.

In what follows, we use the funnel plot in Figure 2 to test for publication selection bias, which could be a severe problem for economic interpretation and statistical inference. Publication selection refers to a process in which results are chosen for their statistical significance (e.g. Brodeur et al. 2016; Andrews and Kasy 2019). The tendency of journal editors to publish only those results that show statistical significance, researchers' willingness to take the presence of a statistically significant effect based on accepted theory and the general predisposition for treating statistically significant results more favourably than 'insignificant' evidence may lead to a distorted picture of the underlying empirical relationship (Card and Krueger 1995, p. 239). In the absence of publication bias, the funnel plot should be symmetric - which would imply that the most precise estimates are close to the true effect, while lowprecision estimates are characterised by wide dispersion. As a consequence, in the case of inexistent publication selection bias the scatter plot should be shaped like an inverted "funnel" (Sutton et al. 2000). Indeed, the observations in Figure 2 seem to be distributed quite symmetrically; however, the right portion of the funnel seems to be "heavier" than the left portion. As visual inspection could be misleading, we continue by using established tests for detecting publication selection bias, which are based on looking at the relationship between the estimated partial correlation and its standard error. If there were no publication bias, the partial correlation and its standard error would not show any systematic relationship. However, if the publication of results were biased, we would find a significant relationship (Egger et al. 1997).

The Funnel-Asymmetry Precision-Effect test (FAT PET) allows us to formally assess the presence of publication selection bias. In doing so, we run the following model:

$$
r_{i j}=\beta_{0}+\beta_{1} S E_{i j}+\varepsilon_{i j}
$$

where $r_{i j}$ is the estimated partial correlation i from study $\mathrm{j}, S E_{i j}$ is its standard error, and $\varepsilon_{i j}$ is the random sampling error. In this equation, the term $\beta_{1} S E_{i j}$ allows for publication selection bias. The hypothesis test of $\beta_{1}\left(\mathrm{HO}: \beta_{1}=0\right)$ can be called the Funnel Asymmetry Test (short: FAT). The relevant question is whether $\beta_{1}$ equals zero, because in this case we could conclude that there is no evidence for publication selection bias (Egger et al. 1997). At the same time, investigating the hypothesis that $\beta_{0}$ is zero (referred to as the Precision-Effect Test, short: PET) allows us to test whether there is an empirical effect that remains after accounting for publication selection. However, the reported empirical estimates come from different data sets with various sources of heteroskedasticity, and they must therefore be expected to have different variances. To address this issue, we estimate equation (3) by using Weighted Least Squares (WLS) with the inverse of the variances as weights. ${ }^{8}$

8 It has been shown that the inverse of the partial correlations' variances are the optimal weights (e.g. Cooper and Hedges 1994). 
We start by reporting the precision-weighted average of the EPL-unemployment partial correlation, obtained from regressing the partial correlation coefficient on a constant term by using WLS (see column (1) of Table 3). Without correcting for publication selection bias, there is evidence of a positive and statistically significant impact of employment protection on unemployment. Note, however, that according to the interpretation guidelines in Doucouliagos (2011), which suggest that a partial correlation below 0.07 can be considered to be small, the (precision-weighted) average partial correlation estimate reported in column (1) is very small in terms of economic relevance. By inspecting Figure 2, we can verify this finding, as the most precise estimates (which receive the highest weights in the WLS estimation) are very close to the zero-effect line, while negative and positive effects with lower precision are widely dispersed. Column (2) of Table 2 then accounts for potential publication selection. It reports the results from estimating equation (3). The FAT results in column (2) provide first evidence for publication bias: the association between the partial correlations and their standard errors is positive and statistically significant, at the $1 \%$ level. The PET results in column (2) suggest that the effect of EPL on unemployment is virtually zero once we correct for publication selection. However, one additional complication for the meta-analysis regarding the effect of EPL on unemployment arises because of the presence of multiple estimates per study. It is too restrictive to assume that pairs of partial correlation coefficients and standard errors are independent within studies. In column (3) of Table 2, we account for potential within-study dependency by clustering the standard errors at the study level. The $\beta_{0}$ coefficient (the intercept) with its size close to zero remains statistically insignificant; and the $\beta_{1}$ coefficient (the standard error) is no longer significant. ${ }^{9}$

To answer the question about the extent of publication selectivity, we can exploit the fact that the FAT coefficient $\beta_{1}$ is a unitless measurement, which makes it possible to use it to assess the magnitude of publication selection bias. Doucouliagos and Stanley (2013) argue that when the FAT is statistically insignificant or if $\left|\beta_{1}\right|<1$, then selectivity is 'little to modest' (Doucouliagos and Stanley 2013, p. 320). In our case, the FAT coefficient is statistically insignificant (after clustering the standard errors at the study level), and it is smaller than one. This means that there is little selectivity. Note that this result derived from the FAT test is consistent with the visual inspection of Figure 2: although the right portion of the funnel is a bit 'heavier' than the left portion, the dispersion of the estimates is relatively wide and symmetric, which does not indicate strong publication selectivity. This finding is also consistent with the theoretical literature review in section 2.1, which shows that there is no clear theoretical prediction regarding a strong EPL effect on unemployment in one direction, so we do not need to expect an inclination of researchers to favour the reporting of results consistent with dominant theory.

Nevertheless, it makes sense to correct for the very mild version of publication selection bias that we detect. By doing so, we have established that, once we correct for publication selectivity, the literature fails to provide overall evidence that employment protect has a practically meaningful (non-zero) average impact on unemployment.

A potentially important drawback of using the partial correlation coefficient is that its distribution is not normal when its value is close to -1 and +1 (Stanley and Doucouliagos 2012, p. 25). In our case, this is unlikely to be a problem, since few EPL-unemployment partial correlations are anywhere near the -1 or +1 bounds (see Figure 2). Nevertheless, we implement the most common solution for this potential

9 We did not estimate the PESEE (precision-effect estimate with standard error) specification, which would use the variance (instead of the standard error) in equation (3). The reason for sticking with the FAT-PET is that when there is no true effect, the model with the standard error is correctly specified and provides a less biased estimate of the precision coefficient (e.g. Stanley and Doucouliagos 2012, p. 66). 
problem, which is to use Fisher's z-transformation (e.g. Dunn and Clark 1969). As can be seen from column (4) in Table 2, the FAT PET results prove robust when we use Fisher's z-transformed partial correlation coefficients. ${ }^{10}$ We have seen that about $75.7 \%$ of all estimates use an EPL variable based on the OECD's methodology. Column (5) shows that the FAT PET results are remarkably robust when we only use this subset of estimates. Another potentially important subset of observations concerns the use of a lagged EPL variable, as several studies use EPL lags to address potential simultaneity bias and allow for slow adjustment of unemployment to increasing EPL. The results reported in column (6) indicate that our statistical inferences remain valid when we focus on this subset of 262 (out of 881) observations.

Overall, the FAT PET results reported in Table 2 have established that, once we correct for potential publication selection bias and cluster the standard errors at the study level, the literature fails to provide overall evidence that employment protection has a practically meaningful (non-zero) average impact on unemployment. However, the results reported in Table 2 do not tell us whether method and data choices are correlated with the reported effect size when we also control for other potential confounding factors. To address this point, the next section will investigate sources of heterogeneity in a multivariate metaregression analysis.

\section{Table 2 / FAT PET results}

\begin{tabular}{|lcccccc|}
\hline & $(1)$ & $(2)$ & $(3)$ & $(4)$ & $(5)$ & $(6)$ \\
\hline & Average effect & FAT PET & FAT PET & $\begin{array}{c}\text { FAT PET } \\
\text { (Fisher's z) }\end{array}$ & FAT PET & FAT PET \\
& all estimates & all estimates & all estimates & all estimates & OECD methodology & Lagged EPL \\
\hline$\beta_{1}$ (SE) & --- & $0.490^{* * *}$ & 0.490 & 0.513 & 0.5423 & 0.797 \\
$\{$ FAT\} & --- & $(0.164)$ & $(0.427)$ & $(0.439)$ & $(0.542)$ & $(0.626)$ \\
$\beta_{0}$ (interc.) & $0.022^{* * *}$ & -0.008 & -0.008 & -0.008 & -0.016 & -0.015 \\
$\{$ PET\} & $(0.004)$ & $(0.028)$ & $(0.011)$ & $(0.029)$ & $(0.034)$ & $(0.047)$ \\
$n$ & 881 & 881 & 881 & 881 & 667 & 262 \\
\hline
\end{tabular}

Notes: The dependent variable is the partial correlation, with the exception of column (4), which uses Fisher's z-transformed partial correlation. Numbers in brackets are standard errors. Standard errors in columns (3)-(6) were clustered at the study level. $\mathrm{n}$ is the number of observations. Column (1) reports results from regressing the partial correlation coefficient on a constant. Estimates reported in column (2)-(6) are based on equation (3). Column (5) restricts the sample to estimates using the OECD's methodology for quantifying EPL. Column (6) uses the subsample of estimates that use a lagged EPL variable. All results were obtained by using Weighted Least Squares (weights based on the inverse of the variances). The FAT tests for the presence of publication selection bias. The PET estimates the average effect of employment protection on unemployment corrected for publication selection bias. ${ }^{*},{ }^{* *},{ }^{* *}$ denote statistical significance at the $1 \%, 5 \%$ and $10 \%$ level, respectively.

10 We did not estimate the PESEE (precision-effect estimate with standard error) specification, which would use the variance (instead of the standard error) in equation (3). The reason for sticking with the FAT PET is that when there is no true effect, the model with the standard error is correctly specified and provides a less biased estimate of the precision coefficient (e.g. Stanley and Doucouliagos 2012, p. 66). 


\section{What factors explain the heterogeneity in reported EPL-unemployment estimates?}

This section addresses the question: what factors contribute to explaining the heterogeneity in the reported results on the EPL-unemployment relationship? The results reported in the literature show excess heterogeneity, i.e. there is more variation than could be expected by measured sampling error. ${ }^{11}$ Hence, we continue by identifying likely sources of heterogeneity.

\subsection{THE MULTIVARIATE META-REGRESSION MODEL}

In line with standard techniques for meta-regression analysis (e.g. Stanley and Doucouliagos 2012), we make the assumption that the ith estimate of the EPL-unemployment partial correlation coefficient from study $\mathrm{j}$, denoted $\mathrm{r}_{\mathrm{ij}}$, is not only influenced by sampling error $\left(\varepsilon_{i j}\right)$, but by a vector of variables $\left(Z_{k i}\right)$ consisting of characteristics that capture differences in the underlying impact of employment protection on unemployment. The meta-regression model can thus be written as follows:

$$
r_{i j}=\beta_{0}+\sum \beta_{k} Z_{k i j}+\beta_{1} S E_{i j}+\varepsilon_{i j}
$$

Note that by including the moderator variables in vector $Z$, we estimate an augmented version of the FAT PET model. By estimating equation (4), we can simultaneously account for publication selection bias (the standard error - SE - is still included) and control for factors that might explain excess heterogeneity.

We estimate equation (4) using WLS with the inverse of the variances as optimal weights. Stanley and Doucouliagos (2017) show that the WLS estimator is preferable to other standard estimators that can be used for meta-regression. WLS is preferred since the estimates do not have equal variances, and because it is important to assign more weight to those estimates that are more precise, since the information provided by more precise estimates can be said to be more valuable. However, we will also provide robustness checks based on applying different estimators. As most of the studies in our metastudy database report several estimates, we correct for potential within-study dependence by clustering the standard errors obtained from the meta-regression model at the study-level. The moderator variables included in the vector $Z$ were already introduced in section 3.3 (see, in particular, Table 1).

\subsection{MULTIVARIATE META-REGRESSION RESULTS}

A few preliminary remarks are in order regarding the interpretation of the coefficients in the multivariate meta-regression models presented below. The models always omit one category (as the reference category) from each group of mutually exclusive and jointly exhaustive dummy variables (e.g.

11 This point becomes evident by conducting Cochran's Q-Test (e.g. Cooper and Hedges 1994), which provides clear evidence that there is excess heterogeneity beyond what could be expected by measured random sampling $(p<0.0001)$. 
unemployment measures, or EPL indices). This is necessary because we would otherwise not be able to estimate the models due to perfect multicollinearity. This implies, however, that the intercept $\beta_{0}$ cannot be interpreted as the "true" effect of EPL on unemployment, because it depends on the reference groups. Other reference specifications would give different estimates of the intercept $\beta_{0}$. Our reference specification is an estimate of the impact of EPL - measured by a summary indicator based on the OECD's methodology - on total unemployment, based on data from OECD countries only. Note that the choice of the omitted dummies in no way influences any of the other estimated coefficients, but it shifts the reference value of the intercept $\beta_{0} \cdot{ }^{12}$ Hence, the coefficients of the moderator variables from each group of mutually exclusive and jointly exhaustive dummy variables allow us to make predictions regarding the impact of EPL on unemployment in a given setting as compared to an alternative setting. For example, the estimated average partial correlation of youth unemployment compared with total unemployment (which is the reference category) can be predicted by adding up the value of the intercept $\beta_{0}$ and of the YouthUnemployment coefficient. Note also that we start from a general-to-specific estimation approach, which is the advice given in prominent guidelines to meta-analysis (e.g. Stanley and Doucouliagos 2012, p. 105). In particular, we remove the variable that had the largest $p$-value in the model with all the coded moderators in Table 1 included, and repeat this step until the p-values of all variables are smaller than $0.1{ }^{13}$ The advantage of this general-to-specific approach is that 'model construction proceeds from a very general model in a more structured, ordered and (statistically valid) fashion, and in this way avoids the worst of data mining'. (Charemza and Deadman 1997, p. 78)

Table 3 shows the general-to-specific results from the multivariate meta-regression analysis. Column (1) is based on using WLS, and the standard errors are clustered at the study level. The FemaleUnemployment variable has a positive and statistically significant coefficient, which indicates that - compared to estimates that use total unemployment (which is excluded as the reference category in the group of unemployment measures) - reported estimates that use female unemployment report a larger unemployment-increasing effect of employment protection. However, our model predicts that EPL only has a small positive impact on female unemployment of 0.09 (obtained by adding the FemaleUnemployment coefficient to the intercept), where the interpretation is based on the interpretation guidelines proposed by Doucouliagos (2011), which suggest that a partial correlation between 0 and 0.07 must be considered to be small. YouthUnemployment and LongTermUnemployment both show a positive coefficient in column (1), but they are not statistically significant. OtherDependentVar is significant at the $10 \%$ level.

The coefficient of the SurveyBased variable is both positive and significant at the $1 \%$ level. This finding suggests that, compared to estimates that use the OECD's EPL methodology, estimates that use EPL variables based on surveys report a stronger relationship between employment protection and unemployment, as the model results predict a moderate unemployment-increasing effect of surveybased EPL of 0.13 . The meta-regression results therefore suggest that the choice of the EPL variable explains an essential part of the variation in reported EPL-unemployment estimates. Notably, this finding can also be verified visually by looking at Figure 2, which shows that most of the survey-based observations are clustered to the right of the vertical zero effect line; but the meta-regression analysis

12 See Gechert (2015, p. 567)

13 Note that we did not exclude dummy variables from groups of variables (see the groups "Unemployment measures", "Employment protection measures" and "Country composition", as well as the estimator details in Table 2), even if they were statistically insignificant. The reason is that by excluding variables from these groups, the interpretation of the respective coefficients in comparison to the omitted reference category would no longer work properly. 
shows that there is indeed an impact of choosing a survey-based EPL variable on the reported results when we also control for other confounding factors.

Several additional findings from the meta-regression reported in column (1) of Table 3 are worth highlighting. First, the results in column (1) of Table 3 indicate that, on average, estimates that use nonOECD countries or a mix of countries do not report significantly different results than estimates based on a sample of OECD countries only. Second, we find that using OLS or FGLS as the preferred estimator has a positive impact on reported results. Third, using multi-year averages of the underlying data (YearAverage) tends to dampen the unemployment effects of EPL. Since the main argument of averaging the data is to allow for more reliable causal interpretations of the estimation results (e.g. Baccaro and Rei 2007), our meta-regression finding concerning the variable YearAverage strengthens our main previous finding that, on average, we cannot reject the hypothesis that EPL has a zero (or even slightly dampening) effect on unemployment in the long run. Fourth, in terms of publication characteristics, the meta-regression results in column (1) indicate that estimates reported in labour journals (such as International Labour Review, or Labour Economics) are slightly smaller than estimates reported in other journals. Finally, product market regulation is found to moderate the impact of employment protection on unemployment, lending support to theoretical views that emphasise interactions between product and labour market regulation (e.g. Griffith 2007; Koeniger and Prat 2007). This finding suggests that empirical researchers that want to model the relationship between EPL and unemployment should pay attention to the inclusion of variables that capture the strictness or extent of product market regulation. In a nutshell, these findings highlight that choices of data and estimation strategy do matter, and they contribute to explaining some of the variation in the results reported in the extant literature.

In columns (2)-(4) of Table 3, we test the robustness of the meta-regression results reported in column (1). We do so by applying different estimators (in columns (2) and (3)) and using a transformation of the dependent variable (in column (4)). More specifically, the random effects model in column (2) introduces an additional between-study variance term to cover differences in the EPL-unemployment estimates that go beyond sampling error and those differences captured by the moderator variables (e.g. Schmidt and Hunter 2014). The robust regression estimator applied in column (3) downweighs observations with larger absolute residuals and, hence, is less fragile to the influence of outlier observations. Finally, column (4) uses Fisher's z-transformed partial correlation coefficients to account for the potential problem that the distribution of the partial correlations is not normal when its values are close to -1 and +1 . The results in columns (2)-(4) show that our baseline results remain largely unaffected when we introduce these robustness checks. The size of some of the coefficients and their standard errors are subject to variations. However, there are two cases in which variables whose coefficients were estimated to be statistically significant in column (1) turn out not to be significant in all the three additional models: the coefficients of the variables EFWIndex loses its significance when we apply Random Effects and when we use Fisher's z-transformed partial correlations; and the variable LabourJournal is not significant when we use either robust regression. Therefore, there is only weaker evidence for a significant impact of the variables EFWIndex and LabourJournal, as they lose statistical significance in some of the robustness checks in columns (2)-(4) of Table 3. 
Table 3 / Multivariate regression results (starting from general-to-specific modelling)

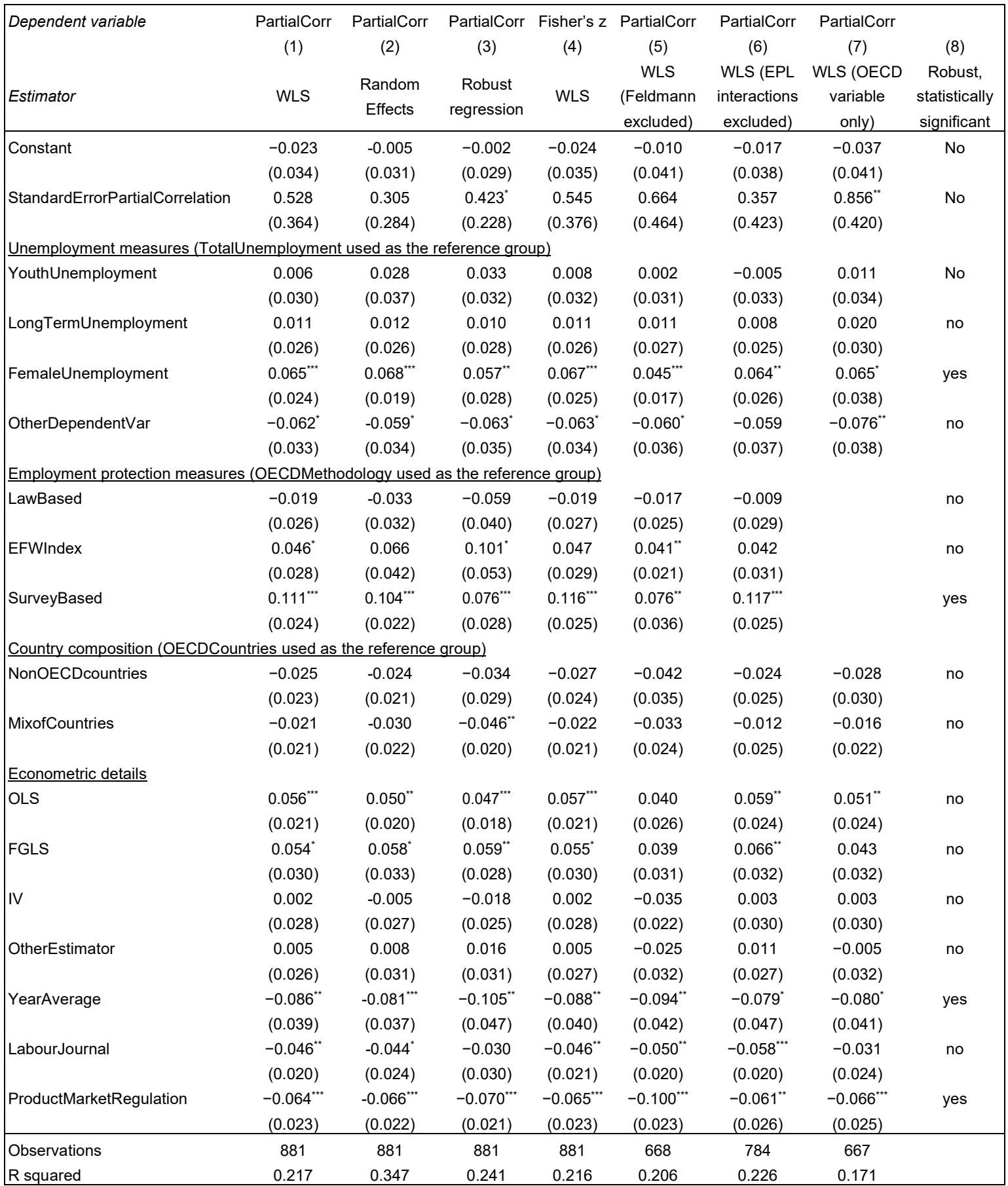

Notes: Standard errors (in parentheses) are clustered at the study level. PartialCorr... Partial correlation. Fisher's z... transformation of the partial correlations (e.g. Dunn and Clark 1969). ${ }^{*},{ }^{* *},{ }^{* * *}$ denote statistical significance at the $1 \%, 5 \%$ and $10 \%$ level, respectively. Details on the variables included are available in Table 1.

The models (5)-(7) in Table 3 provide additional robustness checks by focusing on three sub-samples of the data set. One complication with applying the criteria for including studies in our data set as described in section 3.1 is that we end up with 21 (out of 75) papers written by the same author: over the years 2003 to 2015, Horst Feldmann published 21 peer-reviewed papers on the determinants of 
unemployment. Although these papers do not include duplicates, the results are in part based on only slight variations in the underlying data set and models. A potential point of criticism is, therefore, that these 21 studies by the same author cannot be viewed as independent. Model (5) deals with this point by excluding all EPL-unemployment estimates published in papers by Feldmann, which still leaves us with 668 observations (out of a total of 881). The results in column (5) show only slight variations in the size of the coefficients compared with column (1). All our main regression results hold. The only variable that is no longer statistically significant when we exclude the Feldmann estimates is OLS.

Another potential complication arises from the inclusion of interaction terms of EPL with other variables. Several existing studies have included interaction terms between EPL and macroeconomic shocks, as well as EPL and variables capturing labour market institutions (e.g. Bassanini and Duval 2006; Heimberger et al. 2017). However, only $11 \%$ of all the estimates were based on a specification that also included an interaction term of EPL with another variable. Model (6) in Table 3 excludes all estimates with EPL interaction terms, and our findings remain very robust when using this variation in the underlying sample. Finally, model (7) restricts the sample to those observations that use an EPL variable based on the OECD's methodology for quantifying EPL; this specification also confirms all our main findings. In their book on meta-regression analysis in economics, Stanley and Doucouliagos (2012, p. 105) propose a focus on those research dimensions that have consistent findings across alternative meta-regression model specifications. Column (8) of Table 3 therefore summarises the variables that show significant results in all the meta-regression models, indicating that the variables female unemployment, survey-based EPL, multi-year averages of the underlying data, and product market regulation each have an impact on the reported EPL-unemployment results. 


\section{Discussion and conclusions}

By using meta-analysis and meta-regression methods, this article has analysed the literature concerning the effect of employment protection legislation (EPL) on unemployment. Based on statistically independent estimations (e.g. Lazear 1990; Nickell et al. 2005; Avdagic 2015), some exercises in econometric replication (e.g. Howell et al. 2007; Vergeer and Kleinknecht 2012) and qualitative reviews (e.g. Bean 1994; Blanchard 2006), previous literature has been unable to resolve conflicting theoretical arguments about the direction and magnitude of the effect of employment protection on unemployment. While reported results exhibit wide variation, the question whether method, data and specification choices matter systematically has so far not been answered. This article contributes to the literature by providing the first quantitative analysis of the cumulative evidence and by exploring sources of the wide variation in reported estimates.

The overall empirical evidence is inconsistent with strong non-zero effects of employment protection on unemployment. Indeed, once we account for publication bias, we cannot reject the hypothesis that the average effect is zero. The meta-analytical results point to the following main findings. First, the choice of the EPL variable matters significantly: estimates that use survey-based EPL variables (e.g. Di Tella and MacCulloch 2005; Feldmann 2013) report a significantly stronger unemployment-increasing effect than estimates using EPL indices based on the OECD's methodology, where the latter mainly relies on quantifying relevant information from legal provisions. Second, the meta-regression results also suggest that employment protection has a small unemployment-increasing impact on female unemployment, compared with a zero impact on total unemployment. However, given that only $2.7 \%$ of the observations in our data set use female unemployment rates, this finding should be interpreted with caution and should be scrutinised by future research. Third, using multi-year averages of the underlying data tends to dampen the unemployment effects of EPL. Fourth, product market regulation moderates the effect of EPL on unemployment.

Considering the importance of other factors (such as macroeconomic shocks or changes in production structures) for the determination of unemployment, it is obviously difficult to isolate the effect of EPL on unemployment. Nevertheless, evidence based on the presented meta-analysis of the relevant literature shows that we cannot reject the hypothesis that, on average, the genuine empirical effect of EPL is zero. Notably, this main finding would be consistent with an explanation according to which the effects of employment protection are not universal, as increased employment protection may have different effects on unemployment in different countries or time periods. As a consequence, there might be a lot to learn from careful analysis of case studies, which allow for considering details of the institutional and macroeconomic context of the specific case at hand.

There is no robust evidence for an overall adverse impact of employment protection on unemployment. However, we cannot rule out the possibility that EPL may contribute to high unemployment in some countries, although the evidence clearly rejects an across-the-board policy focus on strict employment protection. In general, employment protection seems to be less important as a factor for explaining unemployment than is often believed, and evidence-based policy-makers should therefore not give 
Wiiw Working Paper 176

advice as if the alleged unemployment-increasing effects of employment protection had been generally confirmed by empirical research.

Where do the results from the meta-analysis point in terms of defining a future research agenda on the relationship between employment protection and unemployment? First, researchers who provide statistically independent estimations could pay attention to the factors that we find to be significant moderating variables of the impact of EPL on unemployment. In particular, the construction of different EPL measures could be subject to critical re-examination (e.g. Myant and Piasna 2017). Second, future work could focus on further improving our understanding about how product market regulation may moderate the effect of employment protection on unemployment, although several studies have already explored this question (e.g. Nicoletti et al. 2000; Kugler and Pica 2004; Koeniger and Praet 2007; Griffith et al. 2007). Third, since very different labour markets may hide behind similar unemployment rates (e.g. Blanchard and Portugal 2001), future research could focus on meta-analysing the effect of employment protection on unemployment duration as well as flows into unemployment to gain a fuller picture. Fourth, this paper has focused on the effects of employment protection on unemployment at the macroeconomic level. The effects, however, may be quite different at the industry level, which could also receive more attention in future research. Finally, given the importance of the question about the determinants of unemployment for the economics discipline as well as for policy-makers, future research could use this study as a point of reference for developing meta-analyses regarding the impact of other (labour market and macroeconomic) variables on various components of unemployment. 


\section{References}

Addison, J., Teixeira, P. (2003), 'The economics of employment protection', Journal of Labor Research, Vol. 24, No. 1, pp. 85-128.

Aleksynska, M., Schindler, M. (2011), 'Labor market regulations in low-, middle- and high-income countries: a new panel database', IMF Working Paper 11/154.

Amable, B., Mayhew, K. (2011), 'Unemployment in the OECD', Oxford Review of Economic Policy, Vol. 27, No. 2, pp. 207-220.

Andrews, A., Kasy, M. (2019), 'Identification of and correction for publication bias', American Economic Review, Vol. 109, No. 8, pp. 2766-2794.

Avdagic, S., Salardi, P. (2013), 'Tenuous link: labour market institutions and unemployment in advanced and new market economies', Socio-Economic Review, Vol. 4, No. 11, pp. 739-769.

Avdagic, S. (2015), 'Does deregulation work? Reassessing the unemployment effects of employment protection', British Journal of Industrial Relations, Vol. 53, No. 1, pp. 6-26.

Baccaro, L., Rei, D. (2007), 'Institutional determinants of unemployment in OECD countries: Does the deregulatory view hold water?', International Organization, Vol. 61, No. 3, pp. 527-569.

Baker, D., Glyn, A., Howell, D., Schmitt, J. (2005), 'Labor market institutions and unemployment: a critical assessment of the cross-country evidence', in: Howell, D. (ed.), Fighting unemployment. The limits of free market orthodoxy, Oxford University Press, Oxford, pp. 72-113.

Ball, L., Mankiw, G. (2002), 'The NAIRU in theory and practice', Journal of Economic Perspectives, Vol. 16, No. 4 , pp. $115-136$.

Bassanini, A., Duval, R. (2006), 'The determinants of unemployment across OECD countries: Reassessing the role of policies and institutions', OECD Economic Studies, Vol. 2006, No. 1, pp. 7-86.

Bean, C. (1994), 'European Unemployment: A Survey', Journal of Economic Literature, Vol. 32, No. 2, pp. 573-619.

Belot, M., van Ours, J. (2004), 'Does the recent success of some OECD countries in lowering their unemployment rates lie in the clever design of their labor market reforms?', Oxford Economic Papers, Vol. 56, No. 4 , pp. 621-642.

Bernal-Verdugo, L., Furceri, D., Guillaume, D. (2012), 'Labor market flexibility and unemployment: New empirical evidence of static and dynamic effects', Comparative Economic Studies, Vol. 54, No. 2, pp. 251-273.

Bernal-Verdugo, L., Furceri, D., Guillaume, D. (2013), 'Banking crises, labor reforms, and unemployment', Journal of Comparative Economics, Vol. 41, No. 4, pp. 1202-1219.

Bertola, G. (1990), 'Job security, employment and wages', European Economic Review, Vol. 34, No. 4, pp. 851-886.

Blanchard O., Wolfers J. (2000), 'The Role of Shocks and Institutions in the Rise of European Unemployment: The Aggregate Evidence', Economic Journal, Vol. 110, No. 462, pp. C1-C33.

Blanchard, O., Portugal, P. (2001), 'What hides behind an unemployment rate: Comparing Portuguese and U.S. labor markets', American Economic Review, Vol. 91, No. 1, 187-207. 
Blanchard O. (2006), 'European unemployment: the evolution of facts and ideas', Economic Policy, Vol. 21, No. 45 , pp. 5-59.

Brodeur, A., Le, M., Sangnier, M., Zylberberg, Y. (2016), 'Star Wars: The Empirics Strike Back', American Economic Journal: Applied Economics, Vol. 8, No. 1, pp. 1-32.

Boeri, T. (1999), 'Enforcement of employment security regulations, on-the-job-search and unemployment duration', European Economic Review, Vol. 43, No. 1, pp. 65-89.

Boeri, T., Jimeno, J. (2005), 'The effects of employment protection: Learning from variable enforcement', European Economic Review, Vol. 49, No. 8, pp. 2057-2077.

Botero, J., Djankov, S., La Porta, R., Lopez-de-Silanes, F., Shleifer, A. (2004), 'The regulation of labor', Quarterly Journal of Economics, Vol. 119, No. 4, pp. 1339-1382.

Cahuc, P., Malherbert, F., Prat, J. (2019), 'The detrimental effect of job protection on employment: Evidence from France', IZA Discussion Paper 12384.

Campos, N., De Grauwe, P., Ji, Y. (2018), The Political Economy of Structural Reforms in Europe, Oxford University Press, Oxford.

Card, D., Krueger, A. (1995), 'Time-series minimum wage studies: A meta-analysis', American Economic Review, Vol. 85, No. 2, 238-243.

Charemza, W., Deadman, D. (1997), New Directions in Econometric Practice, Edward Elgar Publishing, Cheltenham.

Checchi, D., Garcia-Penalosa, C. (2008), ,Labour market institutions and income inequality', Economic Policy, Vol. 23, no. 56, pp. 600-651.

Cooper, H., Hedges, L. (1994), The Handbook of Research Synthesis, Russell Sage Foundation, New York.

Deakin, S., Lele, P., Siems, M. (2007), 'The evolution of labour law: Calibrating and comparing regulatory regimes', International Labour Review, Vol. 146, No. 3-4, pp. 133-162.

Deakin, S., Malmberg, J., Sarkar, P. (2014), 'How do labour laws affect unemployment and the labour share of national income? The experience of six OECD countries', International Labour Review, Vol. 153, No. 1, pp. 1-27.

Di Tella, R., MacCulloch, R. (2005), 'The consequences of labor market flexibility: panel evidence based on survey data', European Economic Review, Vol. 49, No. 5, pp. 1225-1259.

Doucouliagos, H. (2011), 'How Large is Large? Preliminary and relative guidelines for interpreting partial correlations in economics', Deakin University Working Paper SWP 2011/5.

Doucouliagos, C., Stanley, D. (2013), 'Are all economic facts greatly exaggerated? Theory competition and selectivity', Journal of Economic Surveys, Vol. 27, No. 2, pp. 316-339.

Dunn, O., Clark, V. (1969), 'Correlation Coefficients Measured on the Same Individuals', Journal of the American Statistical Association, Vol. 64, No. 325, pp. 366-377.

Dutt, P., Mitra, D., Ranjan, P. (2009), 'International trade and unemployment: theory and cross-national evidence', Journal of International Economics, Vol. 78, No. 1, pp. 32-44.

Duval, R., Furceri, D. (2018), 'The effect of labor and product market reforms: The role of macroeconomic conditions and policies', IMF Economic Review, Vol. 66, No. 1, pp. 31-69.

Egger, M., Smith, G., Scheider, M., Minder, C. (1997), 'Bias in meta-analysis detected by a simple, graphical test', British Medical Journal, Vol. 315, No. 7109, pp. 629-634. 
Eggertsson, G., Ferrero, A., Raffo, A. (2014), 'Can structural reforms help Europe?', Journal of Monetary Economics, Vol. 61, No. 1, pp. 2-22.

Elmeskov, J., Martin, J., Scarpetta, S. (1998), 'Key lessons for labor market reforms: evidence from OECD countries' experience', Swedish Economic Policy Review, Vol. 2, No. 5, pp. 205-252.

Feldmann, H. (2009), 'The unemployment effects of labor regulation around the world', Journal of Comparative Economics, Vol. 37, No. 1, pp. 76-90.

Feldmann, H. (2013), 'The unemployment effect of hiring and firing regulation in developing countries: survey evidence', Applied Economics Letters, Vol. 20, No. 18, pp. 1603-1607.

Friedman, M. (1968), 'The role of monetary policy', American Economic Review, Vol. 58, No. 1, pp. 1-17.

Gechert, S. (2015), 'What fiscal policy is most effective? A meta-regression analysis', Oxford Economic Papers, Vol. 67, No. 3, pp. 553-580.

Griffith, R., Harrison, R., Macartney, G. (2007), 'Product market reforms, labour market reforms and unemployment', Economic Journal, Vol. 117, No. 519, pp. C142-C166.

Grubb, D., Wells, W. (1993), 'Employment regulation and patterns of work in EC countries', OECD Economic Studies, Vol. 21, No. 1993, pp. 7-58.

Gwartney, J., Lawson, R., Hall, J., Murphy, R. (2018), Economic Freedom of the World. 2018 annual report, Vancouver: Fraser Institute.

Heckman, J. (2007), 'Comments on Are Protective Labor Market Institutions at the Root of Unemployment? A Critical Review of the Evidence by David Howell, Dean Baker, Andrew Glyn, and John Schmitt', Capitalism and Society, Vol. 2, No. 1, pp. 1-5.

Heimberger, P., Kapeller, J., Schütz, B. (2017), 'The NAIRU determinants: What's structural about unemployment in Europe?', Journal of Policy Modeling, Vol. 39, No. 5, pp. 883-908.

Holt, H., Hendrickson, J. (2017), 'Turning pink slips into red tape: The unintended effects of employment protection legislation', Contemporary Economic Policy, Vol. 35, No. 3, pp. 421-438.

Howell D., Baker, D., Glynn, A., Schmitt, J. (2007), 'Are Protective Labor Market Institutions at the Root of Unemployment? A Critical Review of the Evidence', Capitalism and Society, Vol. 2, No. 1, pp. 1-73.

International Monetary Fund (2003), 'Unemployment and labor market institutions: Why reforms pay off', IMF World Economic Outlook, April 2003, pp. 129-150.

Koeniger, W., Praet, J. (2007), 'Employment protection, product market regulation and firm selection', Economic Journal, Vol. 117, pp. 521, pp. F302-F332.

Kugler, A., Pica, G. (2004), 'Product market regulations on the Italian labour market', CEPR Discussion Paper 4216.

Layard, R., Nickell, S., Jackman, R. (1991), Unemployment, macroeconomic performance and the labour market, Oxford University Press, Oxford.

Lazear, E. (1990), 'Job security provisions and employment', Quarterly Journal of Economics, Vol. 105, No. 3, pp. 699-726.

Myant, M., Piasna, A. (2017), 'Uses and abuses of the OECD's Employment Protection Legislation Index in research and EU policy making', in: Piasna, A., Myant, M. (eds.), Myths of employment deregulation: how it neither creates jobs nor reduces labour market segmentation, ETUI, Brussels, pp. 23-42.

Nickell, S. (1998), 'Unemployment: Questions and Some Answers', Economic Journal, Vol. 108, No. 448, pp. 802-816. 
Wiiw Working Paper 176

Nickell, S., Nunziata, L., Ochel, W. (2005), 'Unemployment in the OECD Since the 1960s. What Do We Know?', Economic Journal, Vol. 115, No. 500, pp. 1-27.

Nicoletti, G., Scarpetta, S., Boylaud, O. (2000), 'Summary indicators of product market regulation with an extension to employment protection legislation', OECD Economics Department Working Paper 226.

OECD (1994), The OECD Jobs Study: Evidence and explanations, Organisation for Economic Co-operation and Development, Paris.

OECD (1999), Employment Outlook 1999, Organisation for Economic Co-operation and Development, Paris.

OECD (2013), Employment Outlook 2013, Organisation for Economic Co-operation and Development, Paris.

OECD (2016), 'Short-term labour market effects of structural reforms: Pain before gain?', in: OECD

Employment Outlook 2016, pp. 111-168.

Siebert, H. (1997), 'Labor Market Rigidities: At the Root of Unemployment in Europe', Journal of Economic Perspectives, Vol. 11, No. 3, pp. 37-54

Scarpetta, S. (1996), 'Assessing the role of labour market policies and institutional settings on unemployment: a cross-country study', OECD Economic Studies, Vol. 26, No. 1, pp. 43-98.

Schmidt, J., Hunter, F. (2014), Methods of meta-analysis: Correcting Error and Bias in Research Findings, Sage Publications, Newbury Park.

Stanley, T., Doucouliagos, H. (2012), Meta-Regression Analysis in Economics and Business, Routledge Advances in Research Methods, London and New York.

Stanley, T., Doucouliagos, H. (2017), 'Neither fixed nor random: weighted least squares meta-analysis', Statistics in Medicine, Vol. 34, No. 13, pp. 2116-2127.

Stockhammer, E., Klär, E. (2011), 'Capital accumulation, labour market institutions and unemployment in the medium run', Cambridge Journal of Economics, Vol. 35, No. 2, pp. 437-457.

Sutton, A., Abrams, K., Jones, D., Sheldon, T., Song, F. (2000), Methods for Meta-analysis in Medical Research, Wiley, Chichester.

Vergeer, R., Kleinknecht, A. (2012), 'Do Flexible Labor Markets Indeed Reduce Unemployment? A Robustness Check', Review of Social Economy, Vol. 70, No. 4, pp. 451-467. 
IMPRESSUM

Herausgeber, Verleger, Eigentümer und Hersteller:

Verein "Wiener Institut für Internationale Wirtschaftsvergleiche" (wiiw),

Wien 6, Rahlgasse 3

ZVR-Zahl: 329995655

Postanschrift: A 1060 Wien, Rahlgasse 3, Tel: [+431] 53366 10, Telefax: [+431] 533661050 Internet Homepage: www.wiiw.ac.at

Nachdruck nur auszugsweise und mit genauer Quellenangabe gestattet.

Offenlegung nach $\S 25$ Mediengesetz: Medieninhaber (Verleger): Verein "Wiener Institut für Internationale Wirtschaftsvergleiche", A 1060 Wien, Rahlgasse 3. Vereinszweck: Analyse der wirtschaftlichen Entwicklung der zentral- und osteuropäischen Länder sowie anderer Transformationswirtschaften sowohl mittels empirischer als auch theoretischer Studien und ihre Veröffentlichung; Erbringung von Beratungsleistungen für Regierungs- und Verwaltungsstellen, Firmen und Institutionen. 


\section{wiiw}
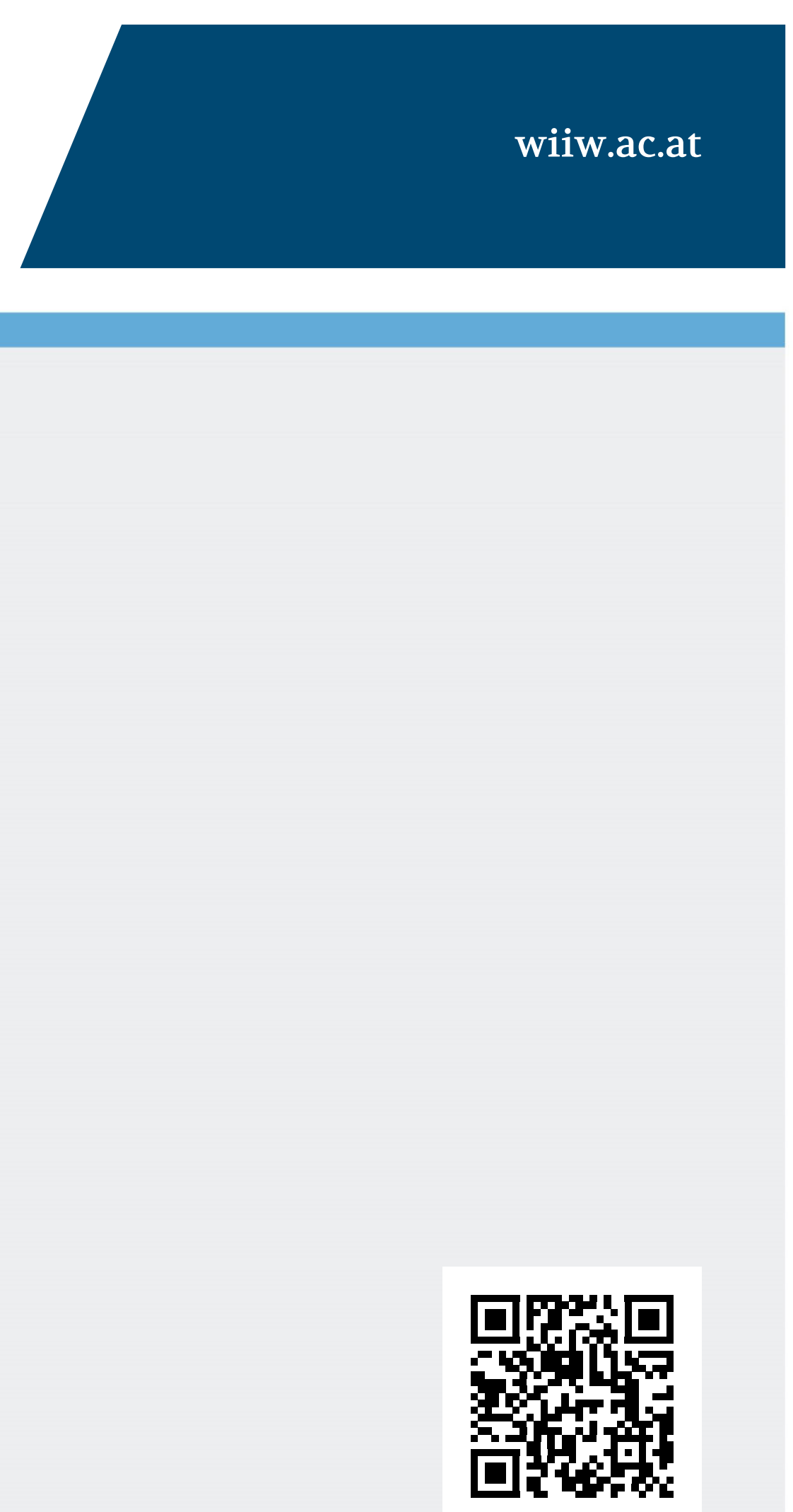

https://wiiw.ac.at/p-5225.html 